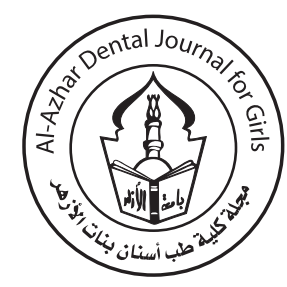

\title{
Evaluation of the Effect of Turmeric Gel and Turmeric Powder as Pulpotomy Medicaments in Primary Teeth
}

\author{
Nouralhouda F. Abd-Allah ${ }^{1 *}$, Mona H. Farid ${ }^{2}$, Magda A. ElMalt ${ }^{3}$
}

Codex : 20/21.10

azhardentj@azhar.edu.eg

http://adjg.journals.ekb.eg

DOI: $10.21608 /$ adjg.2021.23022.1223

Pediatric Dentistry \& Orthodontics ( Pediatric Dentistry, Orthodontics)

\section{KEYWORDS}

Turmeric, Curcumin, Pulpotomy

\begin{abstract}
Purpose: to evaluate the effect of turmeric gel and turmeric powder as pulpotomy medicaments in primary teeth. Materials and Methods: Ninety primary molars in 28 patients, with age range from 4 to 7 years were selected according to inclusion criteria, in each patient two primary molars at least were required for pulpotomy. The patients were allocated into three groups according to the type of pulp dressing material. The follow up periods were 1,3 and 6 months for clinical evaluation. Periapical radiographs were taken at 3 and 6 months recall visits. Results: Results showed all cases in the three groups revealed clinical success at 1 month, 3 as well as 6 months follow up periods. Radiographic study displayed no statistically significant difference between the three groups after 3 months, while there was a statistically significant difference between the three groups after 6 months. Curcumin powder group revealed the highest prevalence of internal resorption followed by Curcumin gel group while Formocresol group revealed the lowest prevalence of internal resorption. However; the difference between survival of the three groups was no statistically significant. Conclusions: Turmeric (curcumin) powder and turmeric (curcumin) gel showed excellent clinical success, acceptable radiographic success and good survival, so the turmeric powder and turmeric gel may be promising biocompatible materials for dressing the radicular pulp after pulpotomy in primary teeth.
\end{abstract}

\section{INTRODUCTION}

The maintenance of primary teeth and their supporting tissues in healthy functioning state is of great importance in keeping arch length and arch circumference as well as mastication, speech, esthetics and good oro-facial development of the child ${ }^{(1-3)}$.

1. Assistant Lecturer of Pedodontics and Oral Health, Faculty of Dental Medicine for Girls, Al-Azhar University, Cairo, Egypt.

2. Professor of Oral and Dental Biology, Former Dean of Faculty of Dental Medicine for Girls, Al-Azhar University, Cairo, Egypt.

3. Assistant Professor of Pedodontics and Oral Health, Faculty of Dental Medicine for Girls, Al-Azhar University, Cairo, Egypt.

* Corresponding author email: nouralhoudafathy.26@azhar.edu.eg 
Pulptomy is a conservative pulp treatment agreed by pediatric dentists. Pulpotomy is a common therapy performed on a primary tooth when caries removal results in pulp exposure with a normal pulp, reversible pulpitis or after traumatic pulp exposure ${ }^{(4,5)}$. Pulpotomy means amputation of the coronal pulp leaving the radicular vital pulp ${ }^{(2,6)}$.

There is a debate over using of formocresol due to its toxic and potential carcinogenic effects ${ }^{(7)}$. Although numerous medicaments are available for pulpotomy, it is important to explore new alternatives that could also present necessary biological and biochemical properties, be safe and easy to handle and have low cost. Traditional medicine is a wonderful resource for new medicines. Turmeric (Curcuma longa) which belongs to the ginger (Zingiberaceae) family is one agent in traditional medicine. Components of turmeric are termed curcuminoids, which comprise mainly curcumin (diferuloylmethane), demethoxycurcumin, and bisdemethoxycurcumin. Curcumin, a yellow colored phenolic compound, is the most important element to which the biological actions of turmeric is attributed ${ }^{(8)}$.

Extensive research studies have proven that curcumin has antioxidant, antibacterial, antifungal, antiviral, anti-inflammatory, antiproliferative, and proapoptotic effects ${ }^{(8,9)}$. Curcumin is interesting agent to study because it possesses desirable therapeutic effects, pharmacological safety and low cost.

\section{MATERIALS AND METHODS}

\section{Preparation of Curcumin gel:}

In this study curcumin gel $2 \%$ was prepared using methylcellulose (MC) ${ }^{(10)}$ Methylcellulose served as the curcumin delivery system. $10 \mathrm{~g}$ of methylcellulose polymer were dispersed in the amounts of purified $60^{\circ} \mathrm{C}$ water by magnetic mixer for $30 \mathrm{~min}$ until a prepared homogenous dispersion was obtained, the remaining amount of water was poured coldly and mixed well. The curcumin pow- der was weighed and dissolved in $100 \%$ ethanol using magnetic mixer and added to the previously prepared MC to obtain a uniform gel. It was then left to evaporate the whole ethanol in warm water-bath, left to cool and kept at refrigerator. The $\mathrm{pH}$ of the prepared gel was measured 7.1 by $\mathrm{pH}$ meter. The gel was prepared at Pharmaceuticals Department, Faculty of Pharmacy for Girls.

This study included 90 primary molars in 28 patients .The patients who had minimum two teeth indicated for pulpotomy were selected from among the patients attending the outpatient clinic of the Pedodontic Department, Faculty of Dental Medicine for Girls Al Azhar University. Research Ethics Committee approval was obtained (REC17065). Full detailed treatment plan was explained to the children' parents and informed written consents for treatment and radiographs were obtained prior to treatment.

\section{Inclusion criteria: ${ }^{(11)}$}

- $\quad$ Age of patients 4-7 years old.

- Deep carious primary teeth with vital pulp.

- No symptoms revealing advanced pulpal inflammation, such as spontaneous pain or history of pain at night.

- Absence of clinical and radiographic sign of pulp degeneration, such as uncontrolled bleeding from the root canal, sensitivity to percussion, swelling or sinus tract, mobility, internal resorption, interradicular, and/or periapical bone destruction and advanced physiological root resorption.

- Teeth should be restorable.

Before treatment, a detailed medical and dental history was obtained in diagnostic sheet, then clinical and radiographic examination were carried out. Radiographic assessment was done by digital periapical radiographs. 


\section{Technique of vital pulpotomy:}

The pulpotomy procedure was performed under local anesthesia and rubber dam isolation. After caries removal with \#330 high-speed pear-shaped carbide bur with airlwater spray, access to a pulp chamber was detected with a probe, the roof of the pulp chamber was removed with large high speed round bur with water spray. Coronal amputation was achieved with sharp spoon excavator and the access was refined with high speed fissure bur, the pulp chamber was irrigated with normal saline to prevent dentin chips from being forced into the radicular pulp (fig.1). Following irrigation, hemostasis was attained by sterile cotton pellet applied to the amputated pulp stumps for 2-3 minutes then removed. Excessive bleeding during pulpal amputation or non-vital teeth were excluded from the study.

The teeth were divided into three groups. Each group involved 30 primary teeth according to sample size calculation. Using alpha $(\alpha)$ level of $(5 \%)$ and Beta $(\beta)$ level of $(20 \%)$ i.e. power $=80 \%$; the minimum estimated sample size was 27 teeth per group. The sample size was increased to 30 teeth per group to compensate for a dropout rate of $20 \%$. Sample size calculation was performed using G*Power Version 3.1.9.2.

Depending upon the group assigned, the amputation site was treated as follows:

\section{Group I (30 primary molars):}

Turmeric (Curcumin) gel was placed directly on the amputation site and a thick mix of zinc oxide and eugenol cement was placed into the coronal pulp chamber followed by glass ionomer restoration and stainless steel crown.

\section{Group II (30 primary molars):}

A mixture of curcumin powder and distilled water in the ratio of 3:1 was placed directly on the amputation site and a thick mix of zinc oxide and eugenol cement was placed into the coronal pulp chamber followed by glass ionomer restoration and stainless steel crown.

\section{Group III (30 primary molars):}

A cotton pellet dampened with formocresol was applied to the amputation site for 5 minutes and removed. A thick mix of zinc oxide eugenol cement was placed into the coronal pulp chamber followed by glass ionomer restoration and stainless steel crown.

The children were recalled for clinical examination after 1,3 and 6 months for the presence of any signs and symptoms in the treated teeth. Periapical radiographs also were taken for all treated teeth at 3 and 6 months follow up visits.

\section{Clinical outcomes:}

Teeth showing the following clinical criteria were considered as success: restoration was intact, no symptoms of pain, no swelling of pulpal origin, no fistula, no tenderness to percussion and no pathological mobility ${ }^{(12)}$.

\section{Radiographic outcomes:}

Teeth showing the following radiographic criteria were considered as success: no pathological internal or external root resorption, no interradicular or periapical radiolucency and no increase in periodontal ligament space ${ }^{(12)}$.

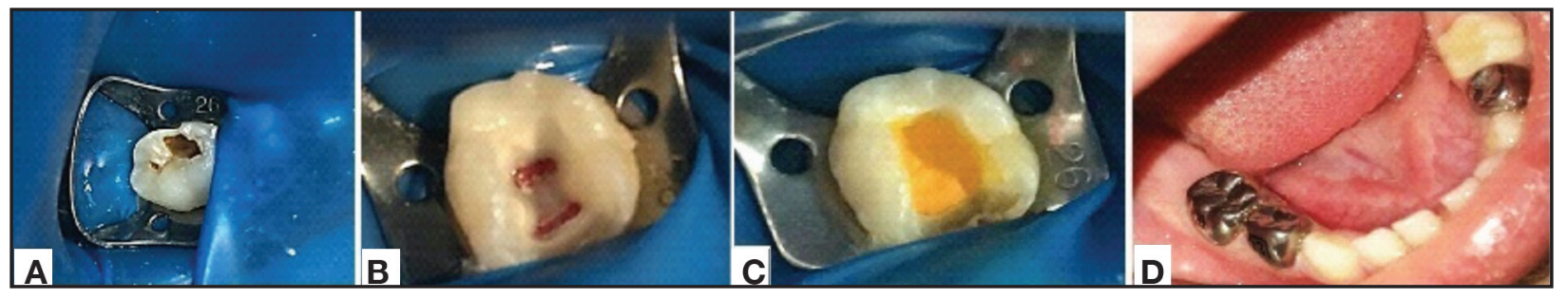

Figure (1) A) selected isolated tooth, B) Technique for pulpotomy, C) curcumin powder applied to the pulpotomized tooth,D) Stainless steel crown coverage. 


\section{Statistical Analysis:}

Qualitative data were presented as frequencies and percentages. Quantitative data were presented as mean and standard deviation values. Chi-square test and Fisher's Exact test were used to compare between qualitative variables in the three groups. Marginal homogeneity test and McNemar's test were used to study the changes within each group. One-way ANOVA test was used to compare between mean age values in the three groups. KaplanMeier survival curve was constructed to calculate survival estimates of the three groups. Comparison between survival times was performed using Log rank test. The significance level was set at $\mathrm{P} \leq 0.05$. Statistical analysis was performed with IBM SPSS Statistics for Windows, Version 23.0. Armonk, NY: IBM Corp.

\section{RESULTS}

\section{Clinical success}

All cases in the three groups showed clinical success at 1 month, 3 as well as 6 months follow up periods. Only one case $(3.3 \%)$ dropped out in Curcumin gel group after 6 months.

\section{Radiographic success}

All cases in the three groups showed no signs of widening of periodontal ligaments, inter-radicular or periapical radiolucency as well as external resorption at 3 and 6 months follow up periods. Only one case (3.3\%) dropped out in Curcumin gel group after 6 months. The only reported radiographic finding was internal resorption.

\section{Internal resorption}

After 3 months; the prevalence of internal resorption was $20 \%, 30 \%$ and $6.7 \%$ in Curcumin gel, Curcumin powder and Formocresol groups, respectively (fig.2). The difference between the three groups after 3 months was non statistically significant $(P$-value $=0.068$, Effect size $=0.244)($ tab.1 $)$.

After 6 months; the prevalence of internal resorption was $20 \%, 40 \%$ and $6.7 \%$ in Curcumin gel, Curcumin powder and Formocresol groups, respectively. The difference between the three groups after 6 months was statistically significant ( $P$-value $=0.022$, Effect size $=0.256)($ table 1$)$. Curcumin powder group showed the highest prevalence of internal resorption followed by Curcumin gel group while Formocresol group showed the lowest prevalence of internal resorption (fig.2).

Table (1): Descriptive statistics, results of Chi-square test and Fisher's Exact test for comparison between prevalence of internal resorption in the three groups

\begin{tabular}{|c|c|c|c|c|c|c|c|c|}
\hline \multirow[t]{2}{*}{ Time } & \multicolumn{2}{|c|}{$\begin{array}{l}\text { Curcumin gel } \\
\qquad(\mathbf{n}=\mathbf{3 0})\end{array}$} & \multicolumn{2}{|c|}{$\begin{array}{l}\text { Curcumin powder } \\
\qquad(\mathbf{n}=\mathbf{3 0})\end{array}$} & \multicolumn{2}{|c|}{$\begin{array}{c}\text { Formocresol } \\
\quad(\mathbf{n}=\mathbf{3 0})\end{array}$} & \multirow[t]{2}{*}{$P$-value } & \multirow[t]{2}{*}{$\begin{array}{c}\text { Effect size } \\
(v)\end{array}$} \\
\hline & $n$ & $\%$ & $\mathrm{n}$ & $\%$ & $\mathbf{n}$ & $\%$ & & \\
\hline $\begin{array}{c}3 \text { months } \\
\text { Internal resorption }\end{array}$ & 6 & 20 & 9 & 30 & 2 & 6.7 & \multirow{2}{*}{0.068} & \multirow{2}{*}{0.244} \\
\hline 3 months Normal & 24 & 80 & 21 & 70 & 28 & 93.3 & & \\
\hline $\begin{array}{l}6 \text { months } \\
\text { Internal resorption }\end{array}$ & 6 & 20 & 12 & 40 & 2 & 6.7 & \multirow{3}{*}{$0.022^{* \dagger}$} & \multirow{3}{*}{0.256} \\
\hline 6 months Normal & 23 & 76.7 & 18 & 60 & 28 & 93.3 & & \\
\hline 6 months Drop-out & 1 & 3.3 & 0 & 0 & 0 & 0 & & \\
\hline
\end{tabular}

*: Significant at $P \leq 0.05,{ }^{\dagger}$ : Fisher's Exact test 


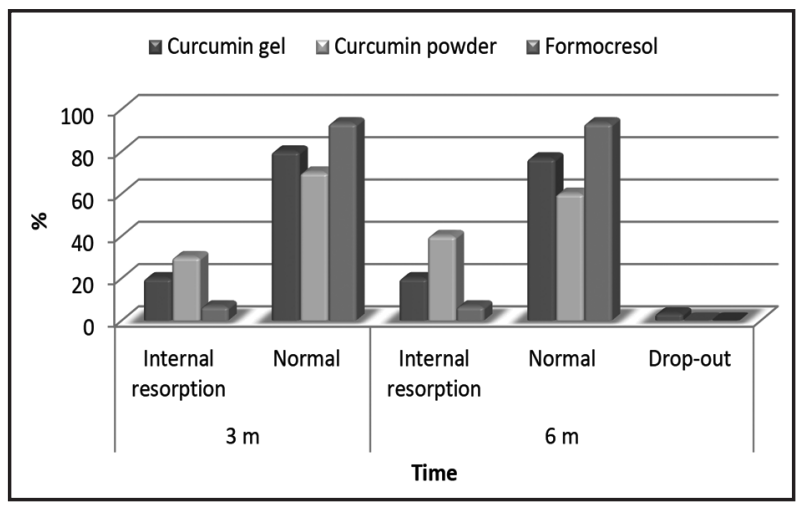

Figure (1) Bar chart representing prevalence of internal resorption in the three groups

As regards the changes in prevalence of internal resorption by time within each group; there was no statistically significant change in prevalence of internal resorption in Curcumin gel, Curcumin powder as well as Formocresol groups $(P$-value $=$ $0.317,0.250$ and 1.000 , respectively).

\section{Survival analysis}

According to Kaplan-Meier survival analysis, Formocresol group showed the highest mean survival time [5.8 months with $95 \%$ Confidence Interval (5.5 - 6.1) months]. Curcumin gel group showed lower mean survival time [5.4 months with 95\% Confidence Interval (5 - 5.8) months]. Curcumin powder group showed the lowest mean survival time [5.1 months with 95\% Confidence Interval (4.5 - 5.6) months]. However; the difference between the survival of the three groups was not statistically significant $(\mathrm{P}$-value $=0.070)($ table 2$)$.

Table (2) Mean survival time (months), 95\% Confidence Interval (95\% CI) and results of comparison between survival of the three groups using Kaplan-Meier survival analysis

\begin{tabular}{|c|c|c|c|c|c|c|}
\hline \multicolumn{2}{|c|}{$\begin{array}{c}\text { Curcumin gel } \\
(\mathbf{n = 3 0 )}\end{array}$} & \multicolumn{2}{c|}{$\begin{array}{c}\text { Curcumin powder } \\
(\mathbf{n}=\mathbf{3 0})\end{array}$} & \multicolumn{2}{c|}{$\begin{array}{c}\text { Formocresol } \\
(\mathbf{n}=\mathbf{3 0})\end{array}$} & \multirow{2}{*}{$\boldsymbol{P}$-value } \\
\hline Mean survival & $95 \%$ CI & Mean survival & $95 \%$ CI & Mean survival & $95 \%$ CI & \\
\hline 5.4 & $5-5.8$ & 5.1 & $4.6-5.6$ & 5.8 & $5.5-6.1$ & 0.070 \\
\hline
\end{tabular}

*: Significant at $P \leq 0.05$

\section{DISCUSSION}

In the current study, curcumin powder was used after mixing with distilled water as a pulpotomy agent similar to a recent study which had used it in rat molars pulpotomy, because of its low water solubility makes it suitable for topical application (13). Furthermore, in another study, curcumin has been revealed to promote cell viability and induce proliferation of primary dental fibroblasts ${ }^{(14)}$.

Curcumin gel $2 \%$ also used in this study as a pulpotomy agent in primary molars while in another study it was used for treatment of experimental periodontitis ${ }^{(10)}$. Gels have good adherence property to the site of application and they are biodegradable and biocompatible ${ }^{(15)}$.

Digital periapical radiograph was used for radiographic assessment to minimize radiation dose and to eliminate processing errors using intra oral sensor size zero to be suitable with children.

According to the clinical outcomes of the present study for Group I (curcumin gel) all cases in this group showed clinical success at 1, 3 and 6 months follow up periods. Only one case (3.3\%) dropped out at 6 months. These results are in accordance 
with a previous study which reported that at 1,3 and 6 months and the total clinical success rate was $100 \%{ }^{(16)}$.

Regarding Group II (curcumin powder), the clinical success rate was $100 \%$ at 1, 3 and 6 month follow up, while in another study used turmeric powder for 3 weeks, 2, 4 and 6 month follow up, the success rate was $100 \%$ at 3 weeks, 2 and 4 months, while it was $93.34 \%$ at 6 months, which could be due to restoration failure ${ }^{(17)}$.

In formocresol group clinical success was $100 \%$ at all observation periods. These results are in accordance with previous studies which reported $100 \%$ clinical success of formocresol at all observation periods ${ }^{(1,2,16,18,19)}$. The clinical success of formocresol pulpotomy in this study may be due to appropriate case selection and suitable use of medicament. The germicidal action, bactericidal action and fixative abilities of formocresol might have contributed to the success.

In this study, internal resorption was regarded as failure. The overall radiographic success rate of curcumin gel group was $80 \%$ at 3 months and $76.7 \%$ at 6 months, because one case dropped out at 6 months. Internal resorption was reported in $20 \%$ of cases at 3 months and 6 months. These results are in agreement with previous study with $100 \%$ radiographic success rate at 1 and 3 month, while radiographic success was $86 \%$ at 6 months and the failure was internal resorption ${ }^{(16)}$.

For Group II (curcumin powder), the overall radiographic success rate was $70 \%$ at 3 months and $60 \%$ at 6 months, the failure was $30 \%$ and $40 \%$ internal resorption at 3 and 6 months. These results are in disagreement with a study on turmeric powder with $100 \%$ radiographic success rate ${ }^{(17)}$. This difference may be due to the previous study used turmeric powder as a crude material, while the current study used the extract which is curcumin powder only. Also the previous study recorded furcation involvement only, while the current study recorded increasing space of periodontal ligament, furcation or periapical radiolucency and internal or external root resorption.

As regards to formocresol group, the radiographic success rate was $93.3 \%$ at 3 and 6 months. Two cases (6.7\%) showed internal resorption at 3 months. This result was in accordance with another study which revealed $100 \%$ radiographic success rate at 6 months ${ }^{(16)}$. While the results of the current study were in disagreement with previous studies which recorded success rates $79 \%{ }^{(20)}, 76 \%{ }^{(21)}, 72 \%^{(22)}$ and $54.3 \%{ }^{(23)}$. This difference may be due to longer periods of follow up ( up to 24 month).

In the present study, internal root resorption was observed more in mandibular first primary molars than mandibular second primary molars. This result was in agreement with a previous study which reported that pulpotomy in first primary molars had $61 \%$ success rate while for second primary molars was $83 \%{ }^{(24)}$.

\section{CONCLUSIONS}

- Turmeric (curcumin) gel and turmeric (curcumin) powder showed excellent clinical success and acceptable radiographic success, so the turmeric powder and turmeric gel are promising biocompatible materials for dressing the radicular pulp after pulpotomy in primary teeth.

- There was no obvious difference between the two physical forms of turmeric (curcumin) used in this study (powder and gel). Also different concentrations of turmeric $2 \%$ gel and full concentration powder showed no significant difference.

\section{REFERENCES}

1. Hugar SM, Deshpande SD. Comparative investigation of clinical/radiographical signs of mineral trioxide aggregate and formocresol on pulpotomized primary molars. Contemp Clin Dent. 2010;1:146-51.

2. Godhi B, Sood PB, Sharma A. Effects of mineral trioxide aggregate and formocresol on vital pulp after pulpotomy of primary molars: An in vivo study. Contemp Clin Dent. 2011; 2:296-301. 
3. Cohn C. Pulpotomy for Primary Teeth with Tricalcium Silicate Material. Inside Dent. 2013; 9:100-2.

4. Camp JH, Fuks AB. Pediatric endodontics: Endodontic treatment for the primary and young permanent dentition. In: Cohen S, Hargreaves KM, eds. Pathways of the pulp. 10th edition, Mosby Elsevier 2011:808-57.

5. Guideline on Pulp Therapy for Primary and Immature Permanent Teeth. Pediatr Dent. 2016;38:280-8.

6. Neamatollahi H, Tajik A. Comparison of clinical and radiographic success rates of pulpotomy in primary molars using formocresol, ferric sulfate and mineral trioxide aggregate (MTA). J Dent Tehran Univ Med Sci. 2006:7-14.

7. Fuks AB. Vital pulp therapy with new materials for primary teeth: new directions and treatment perspectives. Pediatr Dent. 2008;30:211-19.

8. Aggarwal BB, Sung B. Pharmacological basis for the role of curcumin in chronic diseases: An age-old spice with modern targets. Trends Pharmacol Sci. 2009;30:85-94.

9. Jurenka JS. Anti-inflammatory properties of curcumin, a major constituent of curcuma longa: A review of preclinical and clinical research. Altern Med Rev. 2009;14:141-53.

10. Hosadurga RR, Rao SN, Jose J, Rompicharla NC, Shakil M, Shashidhara R. Evaluation of the efficacy of $2 \%$ curcumin gel in the treatment of experimental periodontitis. Pharmacognosy Res. 2014;6:326-33.

11. Waterhouse PJ, Nunn JH, Whitworth JM. An investigation of the relative efficacy of Buckley's formocresol and calcium hydroxide in primary molar vital pulp therapy. $\mathrm{Br}$ Dent J. 2000;188:32-6.

12. Zurn D, Seale NS. Light-cured calcium hydroxide vs formocresol in human primary molar pulpotomies: a randomized controlled trial. Pediatr Dent. 2008;30:34-41.

13. Prabhakar AR, Mandroli PS, Bhat K. Pulpotomy with curcumin: Histological comparison with mineral trioxide aggregate in rats. Indian J Dent Res. 2019;30:31-6.

14. Mandrol PS, Bhat K, Prabhakar AR. An in vitro evaluation of cytotoxicity of curcumin against human dental pulp fibroblasts. J Indian Soc Pedod Prev Dent. 2016;34:269-72.
15. un Nabi SAA, Sheraz MA, Ahmed S, Mustaan N, Ahmad I. Pharmaceutical Gels: A Review. RADS-JPPS .2016; 4: 40-8.

16. Hugar SM, Kukreja P, Hugar SS, Gokhale N, Assudani H. Comparative Evaluation of Clinical and Radiographic Success of Formocresol, Propolis, Turmeric Gel, and Calcium Hydroxide on Pulpotomized Primary Molars: A Preliminary Study. Int J Clin Pediatr Dent. 2017;10:18-23.

17. Purohit RN, Bhatt M, Purohit K, Acharya J, Kumar R, Garg R. Clinical and Radiological Evaluation of Turmeric Powder as a Pulpotomy Medicament in Primary Teeth: An in vivo Study. Int J Clin Pediatr Dent. 2017;10:37-40.

18. Naik S, Hegde AM. Mineral trioxide aggregate as a pulpotomy agent in primary molars: An in vivo study. J Indian Soc Pedod Prev Dent. 2005;23:13-6.

19. Aeinehchi M, Dadvand S, Fayazi S, Bayat-Movahed S. Randomized controlled trial of mineral trioxide aggregate and formocresol for pulpotomy in primary molar teeth. Int Endod J. 2007;40:261-7.

20. Mettlach SE, Zealand CM, Botero TM, Boynton JR, Majewski RF, Hu JC. Comparison of mineral trioxide aggregate and diluted formocresol in pulpotomized human primary molars: 42-month follow-up and survival analysis. Pediatr Dent. 2013;35:E87-94.

21. Sushynski JM, Zealand CM, Botero TM, Boynton JR, Majewski RF, Shelburne CE, et al. Comparison of gray mineral trioxide aggregate and diluted formocresol in pulpotomized primary molars: a 6- to 24-month observation. Pediatr Dent. 2012;34:120-8.

22. Erdem AP, Guven Y, Balli B, Ilhan B, Sepet E, Ulukapi I, et al. Success rates of mineral trioxide aggregate, ferric sulfate, and formocresol pulpotomies: a 24-month study. Pediatr Dent. 2011;33:165-70.

23. Airen P, Shigli A, Airen B. Comparative evaluation of formocresol and mineral trioxide aggregate in pulpotomized primary molars-2 year follow up. J Clin Pediatr Dent. 2012;37:143-7.

24. Vij R, Coll J A, Shelton P, Farooq N S. Caries control and other variables associated with success of primary molar vital pulp therapy. Pediatr Dent. 2004; 26: 214-20. 